\title{
Effect of the operating conditions on the particle size distribution by the suspension polymerization process
}

\section{Efecto de las condiciones de funcionamiento en la distribución del tamaño de partícula por el proceso de polimerización en suspensión}

\author{
RODRÍGUEZ-PIZANO, José Josué†, GRANADOS-RIVERA, Laura Edith, HERNÁNDEZ-ESCOTO, \\ Héctor and CONTRERAS-LÓPEZ, David*
}

Universidad de Guanajuato. Depto. de Ingeniería Química, División de Ciencias Naturales y Exactas. Noria Alta S/N, Guanajuato, Gto. México 36050

ID $1^{\text {st }}$ Author: José Josué, Rodríguez-Pizano / ORC ID: 0000-0002-8204-1281, CVU CONACYT ID: 887231

ID $1^{\text {st }}$ Coauthor: Laura Edith, Granados-Rivera / ORC ID: 0000-0002-0863-4230, CVU CONACYT ID: 867252

ID $2^{\text {nd }}$ Coauthor: Héctor, Hernández-Escoto / ORC ID: 0000-0002-0576-0346

ID $3^{\text {rd }}$ Coauthor: David, Contreras-López / ORC ID: 0000-0003-1384-4766

DOI: $10.35429 /$ EJB.2019.10.6.1.12

Received January 28, 2019; Accepted March 30, 2019

\begin{abstract}
In this research, we focus on the study of the operating conditions that influence on suspension process for obtaining (co)polymers of styrene with polar monomers (copolymers of styrene with acrylate of butyl (S-BA) and copolymers of styrene with vinyl acetate (S-VAc)) using the technique of conventional free radical polymerization (FRP). At higher agitation speed, the reaction performance decreases. Likewise, the influence of the molecular weight of the dispersing agent, in this case polyvinyl alcohol (PVA), influences the polymerization performance was also observed. That is, at a higher molecular weight of PVAs, there is an increase in the particle size of the bead and in the polymerization yield. Finally, there is an influence of the polar part on the copolymer both for the yield and for the particle size of the bead. When obtaining copolymers of S-VAc, the yield is lower compared to the respective styrene homopolymer and higher in the S-BA.
\end{abstract}

Styrene, Suspension, Polar Monomer, Copolymerization, PVA

\begin{abstract}
Resumen
En esta investigación, nos centramos en el estudio de las condiciones operativas que influyen en el proceso de suspensión para obtener (co) polímeros de estireno con monómeros polares (copolímeros de estireno con acrilato de butilo (S-BA) y copolímeros de estireno con acetato de vinilo (S-VAc) utilizando la técnica de polimerización por radicales libres (FRP) convencional. A mayor velocidad de agitación, el rendimiento de la reacción disminuye. Asimismo, la influencia del peso molecular del agente dispersante, en este caso el alcohol polivinílico (PVA), también influye en el rendimiento de la polimerización. Es decir, a un peso molecular más alto de los PVA, hay un aumento en el tamaño de partícula de la perla y en el rendimiento de polimerización. Finalmente, existe una influencia de la parte polar en el copolímero tanto para el rendimiento como para el tamaño de partícula de la perla. Cuando se obtienen copolímeros de $\mathrm{S}-\mathrm{VAc}$, el rendimiento es menor en comparación con el homopolímero de estireno respectivo y mayor en el SBA.
\end{abstract}

Estireno, Suspensión, Monómero Polar, Copolimerización, PVA

Citation: RODRÍGUEZ-PIZANO, José Josué, GRANADOS-RIVERA, Laura Edith, HERNÁNDEZ-ESCOTO, Héctor and CONTRERAS-LÓPEZ, David. Effect of the operating conditions on the particle size distribution by the suspension polymerization process. ECORFAN Journal-Bolivia. 2019. 6-10: 1-12.

\footnotetext{
* Correspondence to Author (email: david.contreras@ugto.mx)

$\dagger$ Researcher contributing first author.
} 


\section{Introduction}

Currently, the polymers area is one of the fastest growing due to the demand of its products in the international market, for this reason this sector needs to invest in research and technology to improve its products or processes to get this type of materials. Polymers have brought great advantages with respect to traditional materials and for their various applications can be used in many sectors of the processing industry. Therefore, they have great versatility and this can be seen in the great development scientific and technological that has allowed the acquisition of new types of materials. $^{1}$

As an example, the preparation of the styrene-maleic anhydride copolymer can be mentioned, which is of great value because it is widely used as a compatibilizing agent in polymer blends and among other uses. ${ }^{2-4}$ Such a copolymer system is generally prepared by conventional free radicals. (FRP) and has the characteristic of presenting broad molecular weight distributions (Đ) 2.4. For this reason, suspension polymerization is widely used in the industry to produce high added value particulate products as separation media for chromatography columns, ion exchange resins and supports for immobilization of enzymes, among other uses. ${ }^{5}$

\section{Background}

The importance of the particle morphology of the polymer (particle size, shape and internal structure) affects the performance of the resin in many important applications and consequently the economic value of the polymeric resin. The morphology of the particles of a polymer resin is often a key quality parameter that must be controlled. Normally, large particles with a relatively uniform size are more desirable. The fine particles can give rise to problems of dust formation, both during handling and bulk processing, also this be a cause of uneven absorption of plasticizers during dry mixing. On the other hand, coarse particles can lead to flow problems during processing and can be a cause for the appearance of fish eyes in the finished product. Finally, large resin particles sometimes do not completely melt during processing, which can significantly impair the appearance and physical properties of the finished articles.
A typical suspension polymerization system is characterized using initiators and monomers that are relatively insoluble in water (this is called continuous phase) and by the fact that the monomer drops are dispersed with aid of a vigorous agitation and small amounts of suspending agents (stabilizers or dispersants). The suspension agents usually used in the process can be of two groups: inorganic compounds insoluble in water such as tricalcium phosphate or water-soluble polymers such as hydroxyethylcellulose or polyvinyl alcohol (PVA).

Several studies ${ }^{6-10}$ have established that the stabilizing properties of PVA during the suspension process are dependent on the concentration, degree of hydrolysis and molecular weight. The suspension process is constituted by the continuous phase that represents most of the reaction medium, where the suspension agent is solubilized and combined with the speed of agitation, it avoids that coalescence does not occur in the dispersed phase as well as control the final particle size of the polymer. The dispersed phase is formed by the monomer and the initiator. The operating conditions that must be taken care of are the reaction temperature, the speed of agitation and the concentration of the dispersing agent in the medium. ${ }^{8,11}$ At the end of the polymerization, pearls are obtained so that their purification process and separation is relatively simple. Thus, the use of the dispersing agent (or suspending agent) is the crucial ingredient for carrying out said polymerization process.

It has been found that at lower molecular weights of the PVA, more stable suspensions are produced than with those of high molecular weight and generating larger particle sizes. With the use of a high molecular weight of PVA have been obtained sizes welldefined particles. It should be noted that the initiator begins inside the drops to initiate the polymerization process. The interaction between the macroradicals is strong enough to facilitate the aggregation of the monomer units. In addition to the growth of the aggregates, it also proceeds by coalescence, forming primary particles that are responsible for the porosity of the formed grains. ${ }^{12,13}$ 
Various reports have been published about the effects of polymerization conditions such as the speed of agitation, type and concentration of the suspending agent, the monomer-water volume ratio, monomer reflux conditions, temperature and conversion. ${ }^{14-16}$ Although the suspension process has been extensively studied, its understanding is still limited. There is a large amount of experimental effort and empirical knowledge to design new resins. The less advanced issues are related to the rheological behavior of the reaction mixture during polymerization and the phenomena of coalescence that determine the particle size distribution in this last stay.13 Obtaining a well-defined size and particle size distribution (PSD) are subject to intensive research for many suspension polymerization processes. $^{17}$

Approximately $80 \%$ of the commercial production of PS and its copolymers is by the process of suspension polymerization. ${ }^{5}$ This material is mainly used for packaging and production of disposable materials, due to its low cost and good processing capacity; the most used form is the expanded one because it is highly required in disposable and construction products, thermal insulators and in the protection of objects packaging.18 The present research is focused on studying some characteristics of the suspension process to carry out the synthesis of styrene copolymers with polar vinyl monomers such as vinyl acetate (VAc) and butyl acrylate (BA). The reason is that within the industrial sphere, this process is still maintained with a trial-and-error approach with few scientific bases, generating negative repercussions economically. 8

The spirit of our study is focused to increasing the knowledge of the factors that govern the polymerization of styrene with polar monomers by the process of suspension to create more advanced and controlled structures, given that this is a part of a project in which some techniques of controlled free radical polymerization (CRP) will be used, in particular nitroxide-mediated polymerization (NMP) and reversible addition-fragmentation chain transfer process (RAFT). Likewise, the intention of obtaining this type of copolymers is to use them as support materials or compatibilizers in mixtures of conductive polymers within the assembly of a solar cell for example.
However, the effectiveness of such applications requires a priori knowledge of the operating conditions and their characteristics of the suspension process of conventional free radical polymerizations and subsequently transfer them to CRP. ${ }^{19}$

Today, our work of group is focused on this type of synthesis approach by mechanical agitation. Therefore, the objectives of this investigation are: 1 . To find which are the operating conditions that obey the suspension process via magnetic stirring, 2 . To control the particle size and distribution of the pearls that are formed and 3. To study the statistical behavior that is focused on said study. All this, accompanying the objectives the analysis by IR-FT, NMR and viscosimetry of solutions.

\section{Materials and Methodology}

Styrene, butyl acrylate, vinyl acetate and benzoyl peroxide (BPO) were of analytical grade (Sigma-Aldrich), the monomers were previously washed to remove the inhibitor by conventional methods. The ethanol was of RA grade. Different molecular weights and degree of hydrolysis of PVA were used as specified by the supplier (see Table 1, Sigma-Aldrich). The experiments of the suspension were carried out in a $250 \mathrm{~mL}$ reactor and the stirring was by magnetic agitation.

The continuous and dispersed liquid phases were prepared as shown in Table $\mathbf{1}$. In the batch suspension polymerization experiments, we investigated the effect of three variables: agitation speed to the reaction system, concentration and molecular weight of the suspension on the conversion profiles, on the molecular weight of the polymeric material obtained, size and distribution of the particle size derived from the suspension process. The experiments were carried out for the homopolymerization of styrene and two copolymerizations of S-BA and S-VAc. 


\begin{tabular}{|c|c|c|}
\hline Polyalcohol & $\begin{array}{l}\text { Molecular weight } \\
\text { (Da) }\end{array}$ & $\begin{array}{l}\text { Degree of } \\
\text { hydrolysis }\end{array}$ \\
\hline PVAl & $13000-24000$ & $87-90 \%$ \\
\hline$P V A 2$ & $30000-70000$ & $87-90 \%$ \\
\hline PVA3 & 89000 & $87-90 \%$ \\
\hline PVA4 & $124000-130000$ & $87-90 \%$ \\
\hline $\begin{array}{l}\text { Continuous } \\
\text { phase: }\end{array}$ & \multicolumn{2}{|c|}{$\begin{array}{l}\text { Distilled water }(100 \mathrm{~mL})+\text { Stabilizer } \\
\text { (PVA) }\end{array}$} \\
\hline $\begin{array}{l}\text { Dispersed } \\
\text { phase: }\end{array}$ & \multicolumn{2}{|c|}{$\begin{array}{l}\text { Monomer(s) + initiator (BPO) } \\
\text { Initiator concentration: } 12.1 \mathrm{~g} / \mathrm{L}=0.05 \\
\text { mol/L }\end{array}$} \\
\hline
\end{tabular}

Table 1 Agents of dispersion and properties of liquids in the two phases in the initial stage of polymerization (85 $\left.{ }^{\circ} \mathrm{C}\right)$

The average molecular weights were determined with a Cannon-Fenske \#25 viscometer and the Mark-Houwink equation. The Mark-Houwink constants for the systems used are presented in Table 2, the percentage is indicated by weight with respect to polar monomer. The PVA solutions were prepared by dissolving the polyvinyl alcohol in water at temperature between 60 and $75{ }^{\circ} \mathrm{C}$. The solutions were kept in agitation until they presented a transparency, so they were filtered and stored before use (for not more than a week).

\begin{tabular}{|c|c|c|}
\hline Polymer $^{a}$ & $\alpha^{b}$ & $\begin{array}{l}K x 10^{3 b} \\
\left(\mathrm{~cm}^{3} / \mathrm{g}\right)\end{array}$ \\
\hline$S$ & 0.530 & 37.0 \\
\hline$S$-VAc $10 \%$ & 0.530 & 37.7 \\
\hline$S-V A c 5 \%$ & 0.530 & 40.6 \\
\hline$S$-VAc $1 \%$ & 0.530 & 44.1 \\
\hline$S-A B \quad 10 \%$ & 0.552 & 34.0 \\
\hline$S-A B 5 \%$ & 0.541 & 35.5 \\
\hline$S-A B 1 \%$ & 0.531 & 36.7 \\
\hline
\end{tabular}

Table 2 Mark-Houwink Constants ${ }^{20}$

a BA: Butyl acrylate; S: Styrene; VAc: Vinyl acetate.

b Referred to $25^{\circ} \mathrm{C}$ and dissolved in toluene.

Conversion profiles. The monomer conversion was calculated by gravimetric analysis of samples taken from the reactor at sampling times chosen by means pipettes ( 0.8 $\mathrm{mm}$ D.I.) and placed on aluminum plates containing an inhibitor solution (hydroquinone).
Towards the end of the reactions, the representative sampling of the particles in suspension became more difficult; despite the agitation in the reactor, the polymer particles tended to settle to the bottom of the reactor because the density of the formed material is significantly higher than that of the water $\left(\rho_{\mathrm{PS}}=1.04 \mathrm{~g} / \mathrm{cm}^{3}\right)$.

\subsection{Synthesis of styrene homopolymer}

A typical procedure for the homopolymerization of styrene to conventional free radicals (FRP) by means the suspension process was carried out using PVA as the dispersing agent. In the dispersed phase, 18,180 $\mathrm{g}$ of styrene $(175 \mathrm{mmol})$ and $0.242 \mathrm{~g}$ of benzoyl peroxide (BPO, $0.1 \mathrm{mmol}$ ) were added, therefore there is a molar ratio of monomer: initiator of 1750: 1 . The synthesis was carried out in a $250 \mathrm{~mL}$ Batch reactor, using $100 \mathrm{~mL}$ of distilled water as a continuous phase (in that phase the PVA was already dissolved, two concentrations of 5 and $10 \mathrm{~g} / \mathrm{L}$ were used), the speed of agitation of the system (three agitation speeds, 300, 500 and $800 \mathrm{rpm}$ were used) at a temperature of $85 \pm 2{ }^{\circ} \mathrm{C}$ until an approximate yield of $80 \%$ was obtained. For the purification of the polymer, we proceeded with filtration by gravity and washed with ethanol (2 times) to remove the remaining PVA on the surface of the beads. It got dry at room temperature until a constant weight was obtained. It was sent to characterize by NMR ${ }^{1} \mathrm{H}$, IR-FT, viscosimetry and sieving to obtain the particle size.

The determination of the NMR ${ }^{1} \mathrm{H}$ spectra was carried out in a Bruker Ascend 400 $\mathrm{MHz}$ equipment of 7.07 Teslas of magnetic field intensity in tubes of $5 \mathrm{~mm}$ external diameter, using deuterated chloroform $\left(\mathrm{CDCl}_{3}\right)$ at room temperature. It worked 16 scans with samples of $25 \mathrm{mg}$ in $0.6 \mathrm{~mL}$ of the deuterated solvent. The chemical shifts $(\delta)$ were measured in parts per million (ppm). Tetramethylsilane (TMS) was used as internal reference for the NMR spectra. To obtain the spectra of FT-IR was in a Perkin-Elmer Spectrum 100 equipment. The samples were analyzed in tablet form by means of a mixture with $\mathrm{KBr}$. The working frequency range was $4000-400 \mathrm{~cm}^{-1}$ using 32 scans and $4 \mathrm{~cm}^{-1}$ resolution. By means of this technique the absorption bands present in the various polymeric compounds obtained were analyzed. 


\subsection{Synthesis of styrene copolymers}

The copolymerization of the styrene was carried out according to the procedure described: "Synthesis of styrene homopolymer" with the difference that the concentration of the polar monomer (butyl acrylate (BA) or vinyl acetate (VAc)) was varied in $10 \%, 5 \%$ and $1 \%$ by weight with respect to styrene added to the system, the free radical initiator was used BPO to maintain a molar ratio of 1750: 1 . It should be noted that for the copolymerizations only the PVA3 was used at a concentration of $5 \mathrm{~g} / \mathrm{L}$ of the dispersing agent.

\section{Results and Discussion}

\subsection{Homopolymerization of styrene}

The following results are related to the use of the PVA3 dispersant agent, it has been selected because is this in the middle part of Table 1, these results are so similar with those obtained the other dispersing agents. The agitation speed in the reaction medium and the concentration of the dispersing agent are natural variables that can be manipulated to control the morphology of the particles in the suspension polymerization reactors, so it is acceptable that these variables do not cause any influence on the kinetics of the polymerization. Figure 1A and $\mathbf{B}$ show the evolution of monomer conversion $(\% \mathrm{X})$ and polymerization rate $\left(\mathrm{R}_{\mathrm{p}}=\mathrm{d} \% X / \mathrm{d} t\right)$ for runs performed at different concentrations with PVA3 at $300 \mathrm{rpm}$ and 85 ${ }^{\circ} \mathrm{C}$. The behavior shown in Figure $\mathbf{1}$ is also observed in the case of the agitation speeds of 500 and $800 \mathrm{rpm}$. It can be seen in Figure 1A that there is a retardation effect in the reaction medium due to the presence of the stabilizing agent since we believe that by adding it to the medium, these agents were used as they were provided without any other purification, which could explain why the reaction is delayed although this phenomenon is not important for the purposes established in the present work however some differences can be observed in the range of conversions from 5 to $80 \%$ but from the practical point of view the reactions end at a conversion of the monomer in about $85 \%$ at $2 \mathrm{~h}$ of reaction, except for the case of the lowest concentration $(0.01 \mathrm{~g} / \mathrm{L})$ which extends until $3 \mathrm{~h}$ of reaction.
This can be explained by the fact that the effect of the immiscibility between the two phases governs more because there is practically no formation of pearls and therefore, there is greater freedom in the dispersed medium for the polymerization reaction, resulting in a larger population of monomer present in the medium and avid radical species of these vinyl type molecules.
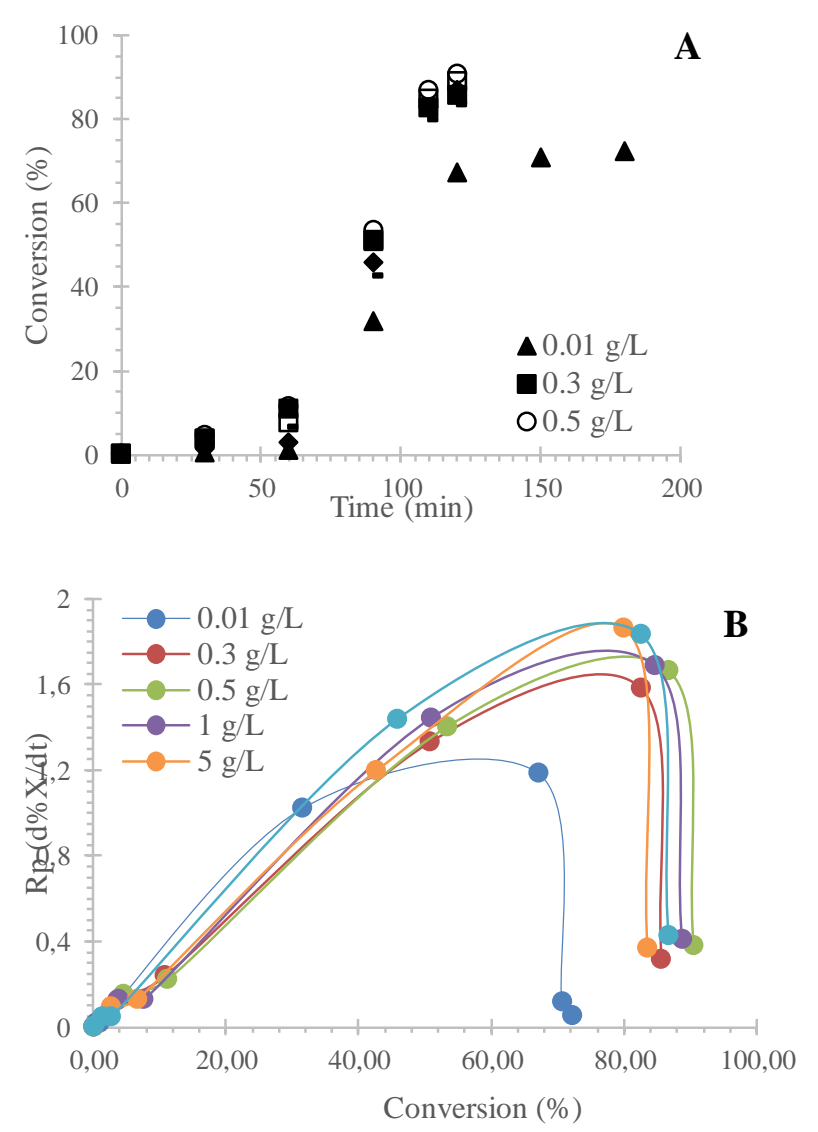

Figure 1 Evolution of monomer conversion (A) and polymerization rates (B) for the suspension polymerization of styrene at $85{ }^{\circ} \mathrm{C}$ and $300 \mathrm{rpm}$ using PVA3

Figure 2 shows the experimental data for the evolution of the average particle size of styrene at different concentrations of PVA3 at the same temperature $\left(85^{\circ} \mathrm{C}\right)$ and at different rates of agitation in the polymerization system. It can be seen that at low concentrations of the suspension agent, the size of the bead is higher than at high concentrations, clearly indicating the low influence of the PVA concentration in the system, which does not have an important participation during the process of pearl formation, governing more the coalescence process and that is according to what is indicated by Lin et al. ${ }^{\mathbf{1 6}}$ 
However, this is not true for high speeds of agitation as it happens at $800 \mathrm{rpm}$ because they govern more the shear forces, allowing the rupture process to be the main phenomenon present in the process. ${ }^{24}$

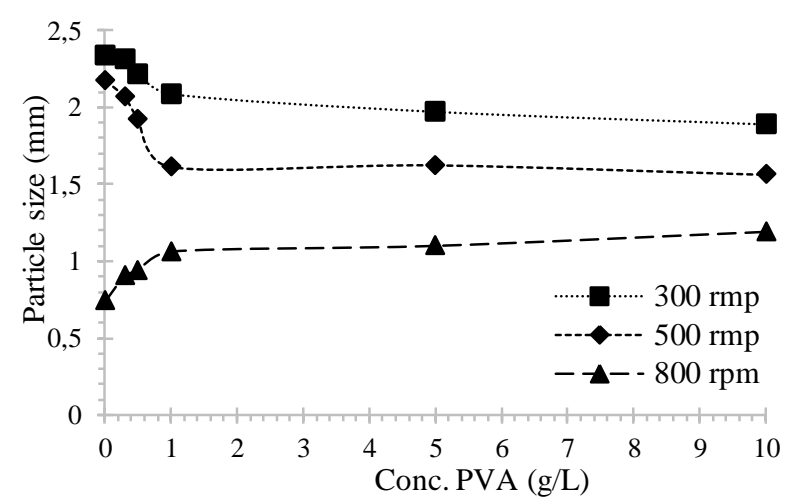

Figure 2 Evolution of the average particle size of polystyrene at different agitation speeds with PVA3

The process of rupture and coalescence comes when the viscosity of the suspended particles is low, and the shearing forces created by the agitation become strong enough to break the particles fused into smaller particles. When the viscosity of the droplets is high such as in the case at moderate to intermediate conversions, the stirring may not be sufficient to interrupt coalesced particles.

In spite this, the protective layer (high coverage) prevents coalescence of the particles in the larger ones and therefore small solid particles will form during the reaction. Only when the concentration of adsorbed polymer segments is not high enough, bridging due to entanglement can be broken by shear forces. In this case the protective layer is not as effective as that of higher concentrations, probably due to the lower density of the polymeric segment and thus coalescence occurs in larger particles. With high molecular weight species, the protective film is thicker than in the case discussed above (due to the much larger molecular weight and size) and therefore coalescence can be effectively prevented even at lower PVA concentrations. $5,12,24$

The average particle size and size distribution in suspension polymerization reactors is important for certain applications. Maintaining the average particle size constant during the scaling of the reactor is a challenge in polymer engineering.
The prediction and control of the final particle size distribution is associated with the evolution of the droplet size distribution in the monomer dispersion of the aqueous continuous phase. We can observe this by means of the effect of the concentration of the suspension agent to different speeds on the particle size (see Figure 2) and on the size distribution (see Figure 4), showing that a reduction in the concentration of PVA produces a larger particle size and a larger particle distribution size, added to the agitation speed imparted to the system (see Figure 3), being the latter an important factor In the dynamic process of coalescence and rupture of the particles in the dispersed medium.

Concluding that, at a higher agitation speed, the average particle size decreases thanks to the effect of the cutting forces that are printed for the formation of the bead.

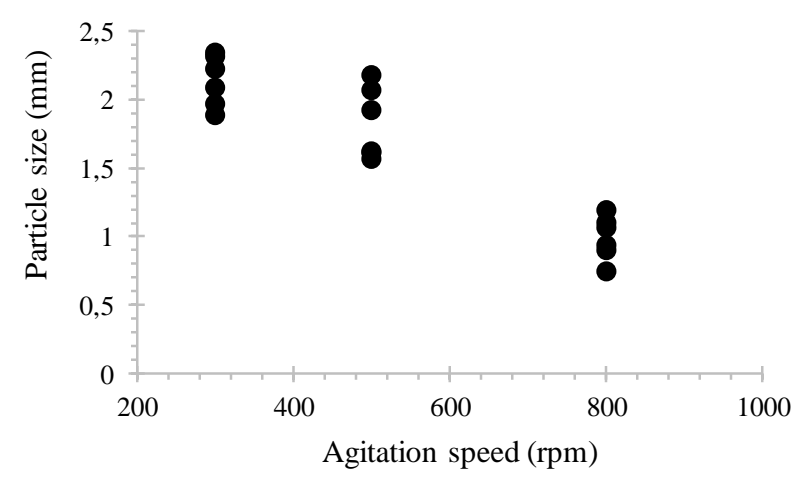

Figure 3 Evolution of the average particle size at different agitation speeds with PVA3

After drying the pearls, the particle size distribution (PSD) was obtained by means of a sieving (standard ASTM sieving method D1291-87) and recording the weight of each size fraction. These results are shown in Figure 4 corresponding to the agitation speeds and in Figure 5 can be seen the evolution of the PSD at different concentrations of the PVA3 dispersion agent.

The distribution presents a tendency of decrease of the average diameter when the concentration of the PVA and the speed of agitation increase. This is due to the breaking of the larger particles and the stabilization of the smaller ones as the PVA is added. 
The effect on the distribution becomes narrower as the agitation speed increases. In the case of the agitation speed of $500 \mathrm{rpm}$, the distribution is narrower than at $300 \mathrm{rpm}$ and the effect of the PVA is the same resulting in a narrower PSD which is not observed at $800 \mathrm{rpm}$ and is due to the existence of a greater shear force in the system. Therefore, as the stirring speed increases the PSD becomes wider. In other words, while the concentration of the dispersing agent increases the PSD decreases and the average size also decreases.

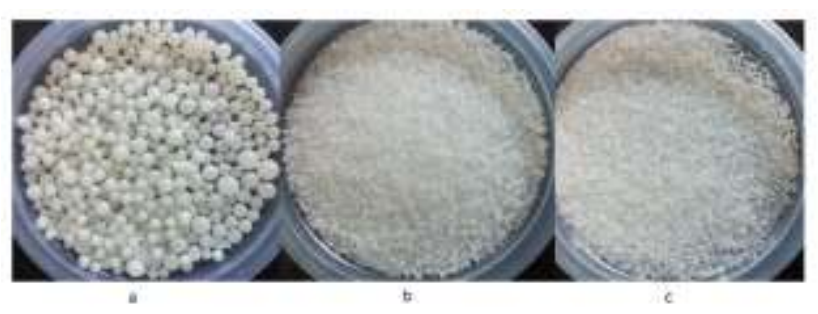

Figure 4 Representative particle sizes at different agitation speeds with PVA3: a) $300 \mathrm{rpm}$, b) $500 \mathrm{rpm}$, c) $800 \mathrm{rpm}$

According to Figure 5, the recurrent modification of the agitation speed and the concentration of the dispersant agent results in a bimodal PSD in the polymerization of the suspension. For purposes of this work, the agitation speed and stabilizer agent concentrations are of interest to observe the change of the final particle size of the polymer, without the need to introduce additional changes in other variables of the reaction conditions of the polymerization or the suspension process itself.

It should be noted that the concentration of $0.01 \mathrm{~g} / \mathrm{L}$ of PVA maintains an erratic behavior during the stabilization process of the suspension and although the amount of the dispersing agent in the system is small, it can be observed that it is sufficient to affect the polymerization process.

This phenomenon can be clearly seen in Figure 5c. At low concentrations of PVA, the surface coverage on the particle is poor and therefore the coalescence will occur when it is in contact with other particles.
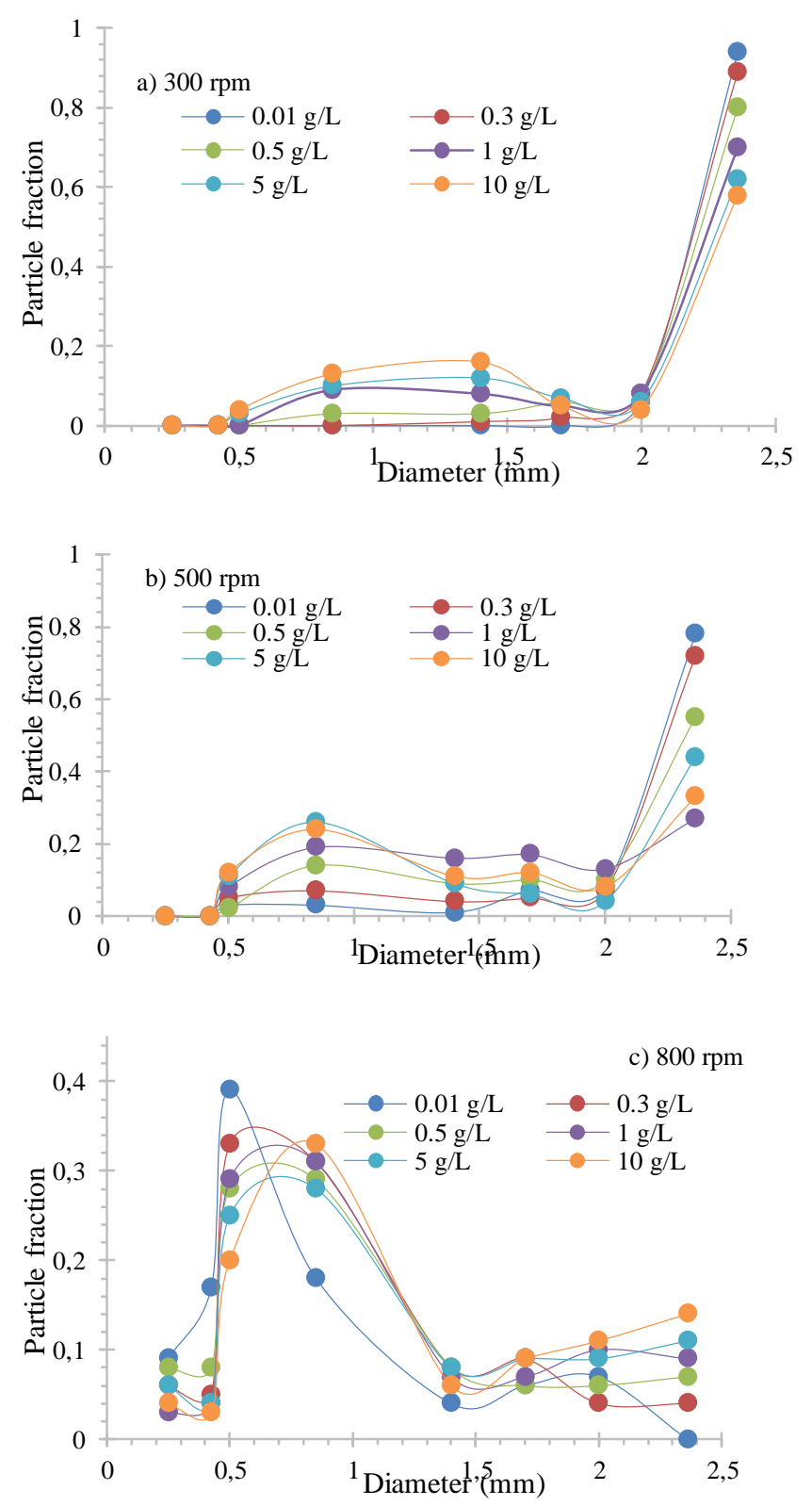

Figure 5 Particle size distribution at different agitation speeds with PVA3, A) $300 \mathrm{rpm}$, B) $500 \mathrm{rpm}$ and C) 800 rpm

The influence that the molecular weight of the dispersing agent has on the size of the particle (bead) in the polymerization of styrene can be observed in Figure 6. The size of the bead has a slight increase and as the speed of agitation decreases, the particle size tends to increase. Therefore, there is a certain trend with the size in relation to the agitation speed since at $300 \mathrm{rpm}$ an average particle size of 2.14 millimeters is obtained, at $500 \mathrm{rpm}$ there is a size of 1.83 millimeters and at $800 \mathrm{rpm}$ a size of 0.99 millimeters. The average size shows a slight tendency to decrease in diameter when the molecular weight of the PVA decreases and this is due to the rupture of the larger particles and to the stabilization of the smaller ones as the dispersing agent is added. 
The results of the suspension polymerization show that the low molecular weight suspension agents (PVA1 and PVA2) are better stabilizers than those of high molecular weight, due to an ageing phenomenon that is related to the formation of a rigid film in liquid-liquid interface.

It has been documented that this phenomenon of ageing decreases with the increase in molecular weight and the degree of hydrolysis that the dispersant has. ${ }^{24,} 25$ However, in cases where it is carried out with high molecular weight suspension agents (PVA3 and PVA4), there is a more definite pearl production.

This is due to the agglomeration of particles that are produced with PVA. The thickness of the polymer adsorption layer increases with the increase in molecular weight and with the increase in particle size. ${ }^{26}$

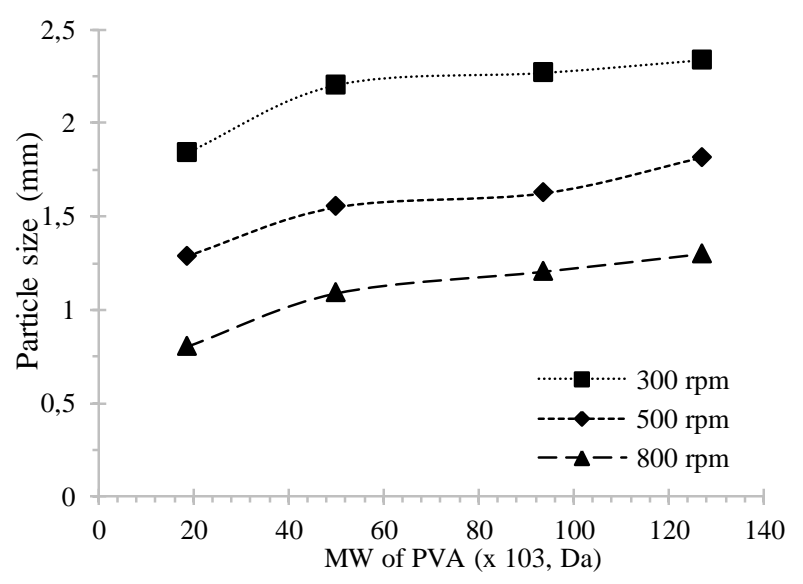

Figure 6 Influence of PVA MW on particle size at different agitation speeds

The influence of molecular weight of the dispersing agent on the molecular weight of the obtained polymer can be seen in Figure 7, this behavior exhibits a proportional increase with the size of the main chain of the PVA and this confirms what was observed in Figure 6 with respect to the agglomeration of the low molecular weight suspension agents and the process of the size of the suspended particle, thickness of the adsorbed layer and physical properties of the reaction of the monomer and polymer.

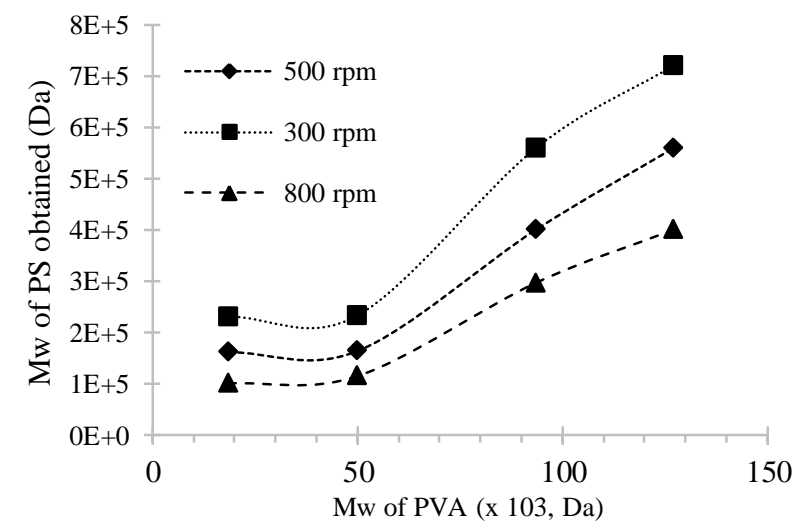

Figure 7 Influence of the molecular weight of the PVA on the molecular weight of the polystyrene obtained at different agitation speeds

It can be seen in Figure 8 the yields of homopolymerization of the styrene with PVA2 and PVA 3 at different concentrations (5 and 10 $\mathrm{g} / \mathrm{L})$ and agitation speeds $(300,500$ and 800 rpm) at $85 \pm 2{ }^{\circ} \mathrm{C}$. According to this, it is obtained a higher yield in the three agitation speeds when a concentration of $5 \mathrm{G} / \mathrm{L}$ is used with any of the dispersing agents, compared with the systems in which it is worked with a concentration of $10 \mathrm{~g} / \mathrm{L}$. This behavior is due to the above described in relation to the coverage of the dispersing agent on the surface of the polymer particle, being low and the coalescence occurs in contact with other particles. Added to that there is a greater space to obtain more freedom during the polymerization process.

Therefore, there is a high probability that the vinyl molecules can be polymerized by the phenomenon of avidity of consumption of the monomers. It is noted that when we used the PVA3, there is a higher performance than when using the PVA2. As already discussed, it is due to both the size and the mobility of the polymer chain of the dispersing agent, so PVA2 maintains a greater proportion of available hydrogen bridges with the continuous phase, which leads to having a lower yield of the polymer formed. 


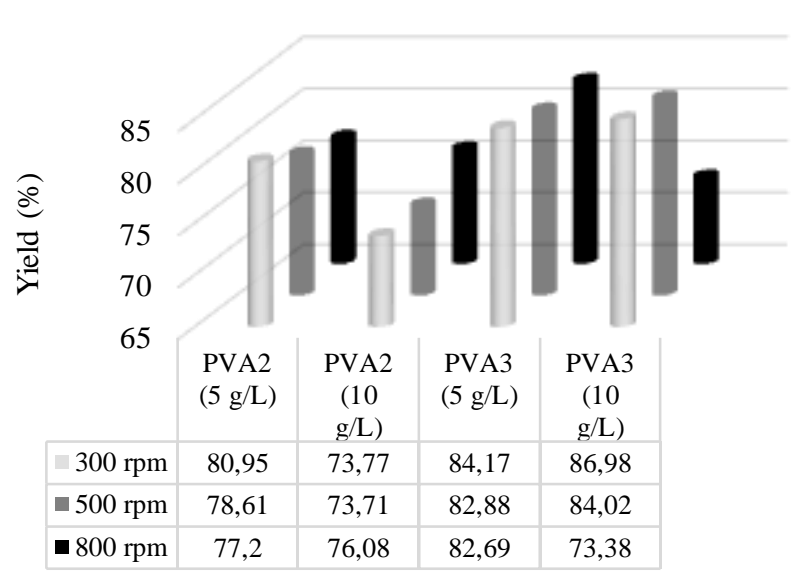

Figure 8 Performance of styrene homopolymers at different agitation speeds by the suspension process. The parentheses indicate the concentration of the dispersing agent

\subsection{Copolymerization with Vinyl Acetate}

According to what was observed during the styrene homopolymerization process, there are copolymerization similar behaviors, so that only the results obtained for the styrene-vinyl acetate copolymers (S-VAc) and for the styrene-butyl acrylate system (S-BA) focused on the yields at different concentrations of the polar comonomer $(10,5$ and $1 \%$ by weight in the feed in relation to styrene). We work with PVA2 and PVA3 along with what has already been discussed because they are the ones that present satisfactory results during the suspension process in polymerization.

For the S-VAc system, it is observed in Figure 9 the yields obtained at different concentrations of vinyl acetate to form the corresponding copolymer, identifying that at the concentration of $1 \%$ by weight of the polar monomer in 10 and $5 \mathrm{~g} / \mathrm{L}$ of the PVA3 lower yields are obtained comparing with the corresponding result of the homopolymerization of the styrene, otherwise with the use of the PVA2 at a concentration of $10 \mathrm{~g} / \mathrm{L}$.

This is to the affinity that exists between polyvinyl acetate and PVA, due to its physicochemical characteristics, which may be forming some type of intermolecular bonds such as hydrogen bridges mainly with the low molecular weight dispersion agent. Finally, there are better yields of the polymerization process with the use of PVA2 than with PVA3.
From the point of view of the reactivity ratios to the $\mathrm{S}$-VAc system $\left(\mathrm{r}_{1}=57.8, \mathrm{r}_{2}=0.08\right),{ }^{20}$ it indicates that polystyrene type radicals react with vinyl acetate at a speed close to 0.02 which can react with the styrene itself if both monomers are present at the same concentration. A similar interpretation can be made with the radicals derived from the VAc, which indicates that it reacts with styrene at a rate of 12.5 times that with vinyl acetate at the same concentration. This allows us to explain that there are lower yields compared with the homopolymerization of styrene. It should be noted that since $r_{1}$ is much larger than $r_{2}$, the copolymer formed contains long sequences of styrene units interspersed with occasional units of vinyl acetate generating a copolymer with a random tendency. ${ }^{27}$

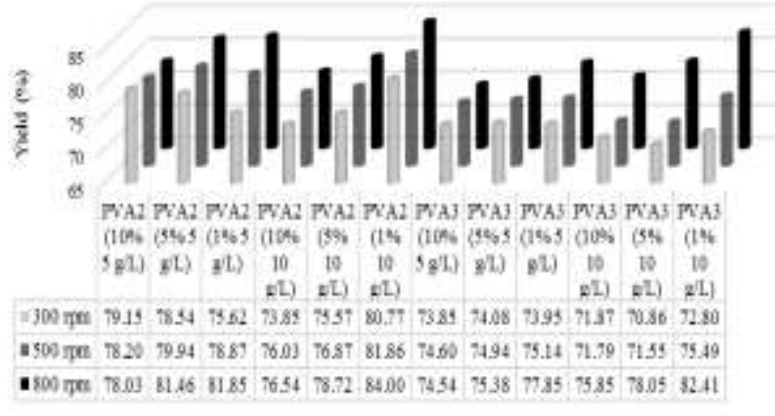

Figure 9 Yield of styrene-vinyl acetate copolymers using PVA2 and PVA3

With respect to the FT-IR spectrum of the (co) polymer S-VAc at $10 \%$ by weight in the feed with respect to styrene and obtained by the suspension process using the PVA3. It was analyzed qualitatively, and its corresponding bands can be observed in Figure 10, the copolymer exhibits the same characteristic absorption bands shown by the homopolymer units.

In this spectrum, a band is shown in $2915 \mathrm{~cm}^{-1}$ representing the vibration of $\mathrm{CH}$ from the methyl, methylene and methine that are present in the main chain of the polymer, the bands in 1941, 1878 and $1804 \mathrm{~cm}^{-1}$ correspond to a monosubstitution in the aromatic ring belonging to the unit of styrene, in the same way we can observe a signal in $1723 \mathrm{~cm}^{-1}$, characteristic of the elongation type vibration of a carbonyl group that corresponds to the acetate group. 
The signal at $1598 \mathrm{~cm}^{-1}$ represents the elongation vibration of a $\mathrm{CC}$ double bond of aliphatic type, as we observe in 1487, 1454 and $1373 \mathrm{~cm}^{-1}$ represent the deformation vibration of a $\mathrm{CH}$ bond of methyl, methylene and methine groups, the band that confirms the existence of a CO bond is at $1269 \mathrm{~cm}^{-1}$.

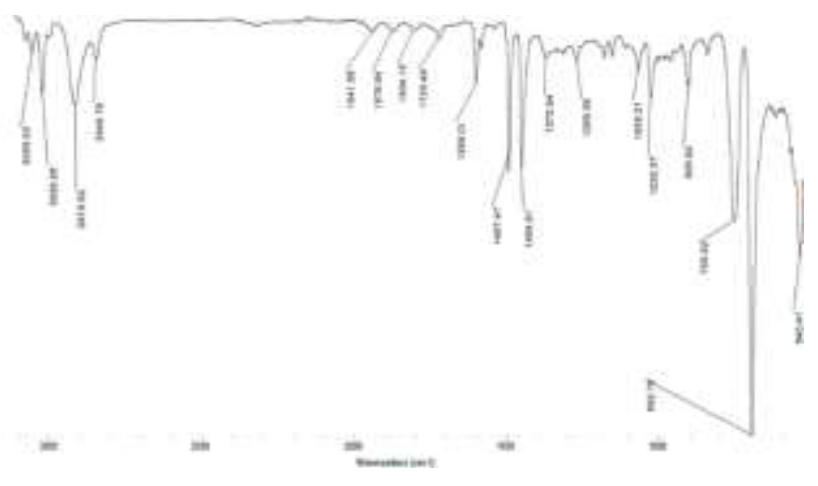

Figure 10: IR-FT spectrum of the $10 \%$ styrene-vinyl acetate copolymer in the feed

In Figure 11 (as in the case of the FTIR, a comparison was made with the homopolymer of styrene), in the region between 0.8 to $1.0 \mathrm{ppm}$ are the contributing signals of the VAc in the copolymer corresponding to methyl, also observed that in 1.2 to $2.0 \mathrm{ppm}$ are the protons that are due to the methylene and methine that make up the main chain of the polymer and a group in 2.05 and $2.2 \mathrm{ppm}$ that are due to the methine (-CH-) that bound the ester group of the acetate. With respect to the contribution of styrene, the signals in the region of 6.3 to $7.1 \mathrm{ppm}$ are due to the aromatic protons.

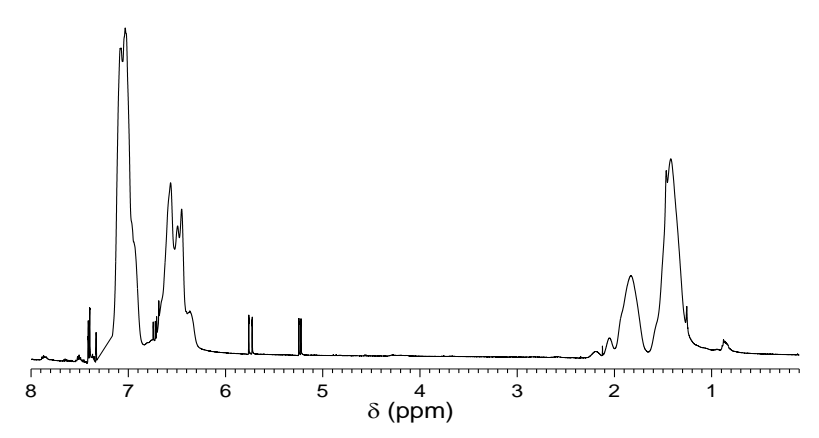

Figure $11 \mathrm{RMN}{ }^{1} \mathrm{H}$ spectrum of styrene-vinyl acetate copolymer at $10 \%$ in the feed with respect to styrene

\subsection{Copolymerization with Butyl Acrylate}

The yields of copolymers of styrene with butyl acrylate, these can be seen in Figure 12. It is generally appreciated that by increasing the concentration of the polar monomer in the medium and the concentration of PVA.
The polymer conversion increases in both cases, this may be due to the interactions exerted by the polar monomer in the reaction medium, the formation of the copolymer is favored when it is in a greater percentage. Although we can notice that using the PVA3 has a higher yield than with the PVA2. This could be related to the configuration that the PVA3 acquires in the reaction medium because it is a larger chain, having a ball configuration and grateful to this, it does not allow it to easily form intermolecular links with the continuous phase as it would be the case of PVA2. The chain of polymer is considerably shorter and can acquire a linear configuration to have a better mobility and form intermolecular bonds with the continuous phase and the polar monomer, decreasing the yield of the obtained polymer.

Now, from the point of view of the reactivity indexes presented by the S-BA system $\left(r_{1}=0.698, r_{2}=0.164\right),{ }^{20}$ it indicates that the polystyrene type radicals react with butyl acrylate at a close speed of 1.43 that you can react with the styrene itself if both monomers are present at the same concentration. A similar interpretation can be made with the radicals derived from $\mathrm{BA}$, which indicates that it reacts with styrene at a rate of 0.03 times that with butyl acrylate at the same concentration. This allows us to explain that there are higher yields compared with the homopolymerization of styrene. It should be noted that since $\mathrm{r} 1$ is slightly larger than $\mathrm{r} 2$, the copolymer formed contains sequences of styrene units interspersed with butyl acrylate units, generating a copolymer with an alternating tendency. ${ }^{27}$

The FT-IR spectrum of the (co) polymer at $10 \%$ by weight in the feed with respect to the styrene obtained by the suspension process using the PVA3, was analyzed qualitatively and its bands can be observed in Figure 13, where it was carried out a comparison between these materials. The copolymer exhibits the same characteristic absorption bands shown by the homopolymer units. 


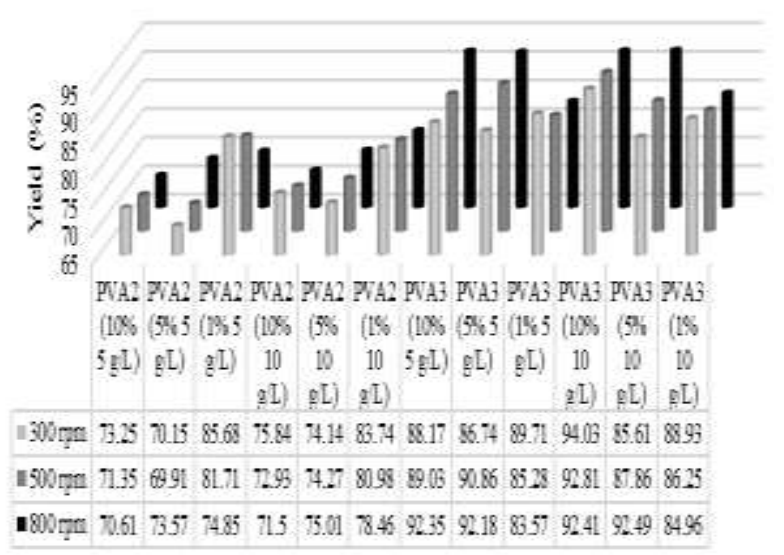

Figure 12 Performance of styrene and butyl acrylate copolymers using PVA2 and PVA3

It can be seen in the FT-IR spectrum of the styrene-vinyl acetate copolymer In this spectrum, a band is shown in $2912 \mathrm{~cm}^{-1}$ representing the vibration of $\mathrm{CH}$ from the methyl, methylene and methine that are present in the main chain of the polymer, the signals in 1943, 1871 and $1800 \mathrm{~cm}^{-1}$ correspond to a monosubstitution in the aromatic ring belonging to the premiere unit, in the same way we can observe a signal in $1725 \mathrm{~cm}^{-1}$.

The characteristic of the vibration of elongation type of a carbonyl group corresponding to the acrylate group.

The signal at $1594 \mathrm{~cm}^{-1}$ represents the elongation vibration of a $\mathrm{CC}$ double bond of aliphatic type, as we observe in 1492, 1443 and $1375 \mathrm{~cm}^{-1}$ represent the deformation vibration of a $\mathrm{CH}$ bond of methyl, methylenes and methine groups, the band that confirms the existence of a CO bond is at $1269 \mathrm{~cm}^{-1}$.

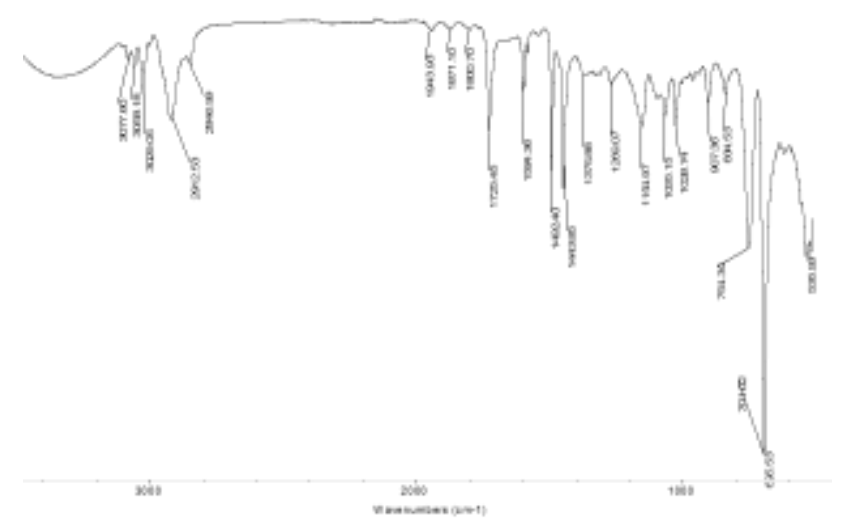

Figure 13 IR-FT spectrum of $10 \%$ by weight styreneacrylate copolymer in the feed
In Figure 14, in the region between 0.5 to $0.8 \mathrm{ppm}$ are the contributing signals of the BA in the copolymer corresponding to methyl, it is also observed that in 0.8 to $1.8 \mathrm{ppm}$ are the protons that are due to the methylene and methine that make up the main chain of the polymer and a group in 1.8 and $2.0 \mathrm{ppm}$ that are due to the methine of the main chain $(-\mathrm{CH}-)$ that binds the ester group of the acrylate. There is a multiplet corresponding to the methylene ($\mathrm{CH}-)$ of the butyl after the acrylate ester. With respect to the contribution of styrene, the signals in the region of 6.0 to $6.9 \mathrm{ppm}$ are due to the styrene aromatic protons.

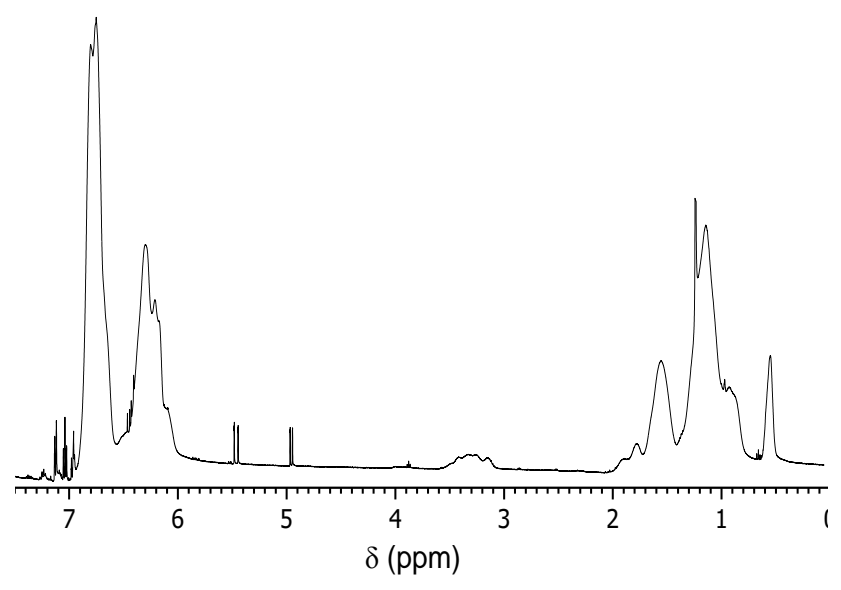

Figure 14 RMN ${ }^{1} \mathrm{H}$ spectrum of styrene-10\% butyl acrylate copolymer in the feed

\section{Conclusions}

According to the observed, it was found that by decreasing the molecular weight and increasing the concentration of the dispersant agent (PVA), there is a lower conversion in the homopolymers of styrene. The influence of the speed of agitation is noticeable when increasing it, as the distribution of particle size is less polydisperse at lower speed.

On the other hand, it was found that by decreasing the concentration of vinyl acetate in the reaction medium, this favors the formation of the corresponding copolymer with a high concentration of dispersant agent.

In the case of styrene and butyl acrylate copolymers, it was found that by increasing the concentration of the polar monomer and the concentration of the dispersing agent, the conversion of the corresponding copolymer is favored. 
Based on the above, this is a very good approximation to the knowledge of the optimal conditions for obtaining this type of styrene polymers.

\section{Acknowledgements}

David Contreras-López acknowledges the financial support of this research by PRODEP through the grant for project DSA/103.5/16/10374.

\section{References}

(1) Utracki LA. Polymer Blends Handbook: Kluwer Academic Pub; 2002

(2) Wu Y, Zhang H, et al. Journal of Applied Polymer Science. 134(36), 45281 (2017)

(3) Wu S, Wang L, et al. Journal of Applied Polymer Science. 134(35), 45251 (2017)

(4) Khan DM, Kausar A, et al. Fullerenes, Nanotubes and Carbon Nanostructures. 24(3),202 (2016)

(5) Ferdinand Rodriguez CC, Christopher K. Ober, Lynden Archer. Principles of Polymer Systems. Sixth Edition ed. USA: CRC Press; 2014

(6) Ramirez JC, Herrera-Ordonez J, et al. Polymer 47(10),3336 (2006)

(7) Hong S, Albu R, et al. Polymer International. 55(12), 1426 (2006)

(8) Zhang C, Li X, et al. Journal of Applied Polymer Science. 133(48), 44270 (2016)

(9) Lu Y, Liu X, et al. Journal of Applied Polymer Science. 134(32),45111 (2017)

(10) Patnam PL, Ray SS, et al. Journal of Applied Polymer Science. 134(13), 44645 (2017)

(11) Lenzi MK, Cunningham MF, et al. Journal of Applied Polymer Science.96(5), 1950 (2005)

(12) Vivaldo-Lima E, Wood PE, et al. Industrial \& Engineering Chemistry Research. 36(4), 939 (1997)
(13) Dowding PJ, Vincent B. Colloids and Surfaces A: Physicochemical and Engineering Aspects. 161(2), 259 (2000)

(14) Jalili K, Abbasi F, et al. Journal of Cellular Plastics. 45(3), 197 (2009)

(15) Castor CA, Sarmoria C, et al. Macromolecular Theory and Simulations. 23(8), 500 (2014)

(16) Lin W, Biegler LT, et al. Chemical Engineering Science. 65(15), 4350 (2010)

(17) Kalfas G, Yuan H, et al. Industrial \& Engineering Chemistry Research. 32(9), 1831 (1993)

(18) Ballner D, Herzele S, et al. ACS Applied Materials \& Interfaces. 8(21), 13520 (2016)

(19) Contreras-López D, Albores-Velasco M, et al. Journal of Applied Polymer Science. 134(29), 45108 (2017)

(20) Brandrup J, Imnergut EH, et al. Polymer Handbook. 4th ed. N. Y., USA: John Wiley \& Sons, Inc.; 1999

(21) Tefera N, Weickert G, et al. Macromolecular Chemistry and Physics. 195(9), 3067 (1994)

(22) Almog Y, Levy M. Journal of Polymer Science: Polymer Chemistry Edition. 19(1), 115 (1981)

(23) Regina-Mazzuca AM, Ark WF, et al. Industrial \& Engineering Chemistry Product Research and Development 21(2), 139 (1982)

(24) Konno M, Arai K, et al. Journal of Chemical Engineering of Japan. 15(2), 131 (1982)

(25) Zhang C, Li X, et al. Journal of Applied Polymer Science. 133(48), 21544 (2016)

(26) Rodrigo R, Toro CA, et al. Journal of Applied Polymer Science. 124(2), 1431 (2012)

(27) Hagiopol C. Copolymerization. Toward a systematic approach. New York: Kluwer Academic/Plenum Publisher; 1999 